\title{
Study of Thermo-Mechanical Properties of Polypropylene and Low Density Polyethylene Composite Material
}

\author{
S. PARMJIT, VIPAN K SOHPAL * and RAJESH K SHARMA \\ PG Research Scholar, Beant College of Engineering \& Technology, Gurdaspur, Punjab India. \\ ${ }^{*}$ Corresponding author E-mail: vipan752002@ gmail.com \\ http://dx.doi.org/10.13005/ojc/320151
}

(Received: January 25, 2016; Accepted: February 23, 2016)

\begin{abstract}
The goal of this research paper is preparation and characterization of the mechanical and thermal properties of polypropylene (PP) and linear low density polyethylene (LLDPE) base polymer that blend filled with talc and magnesium carbonates.
\end{abstract}

Key words: Polypropylene, Low density polyethylene, Magnesium carbonate, Talc, Thermo-mechanical properties.

\section{INTRODUCTION}

From ancient periods, the quest for new materials has been developed. PP applications are very useful in engineering materials for the automotive, electrical appliances and packaging manufacturing due to its excellent properties such as rigidity and stiffness. Oil resistance and thermal stability is usually confined due to its low impact strength and Young's modulus, particularly at low and high-temperature loading conditions. These PP impediments can be considerably enhanced by blending PP with other polymers. LLDPE is also similar polymer like PP. It is commonly used in automotive and packaging industries. The blending of two or more polymers is a cheaper and more efficient option, not only for the development of polymers with new properties but also for recycling of materials. It is possible to achieve improvement in properties such as modulus, yield stress, and tensile strength by an appropriate combination of polymer components. PP and LLDPE are deemed to be compatible in the liquid state.

PVC and ENR blend prepared using Brabender plasticorder by the melt flow behavior of ENR decreases the Brabender torque, increases the melt flow index (MFI), and decreases the melt viscosity of PVC in the blends ${ }^{1}$. Species of wood flour added with PP and one or two broad particle-size distributions. On increasing wood flour content, flexural and tensile modulus, density, 
heat deflection temperature, and notched impact energy increased, and some of the properties are decreased ${ }^{2}$.Viscoelastic properties of a 60/70 penetration grade bitumen improved. Stability tests performed combining oscillatory flow and microscopy results disclose that blends with the higher polymer proportion (3\%) are susceptible of phase separation after $24 \mathrm{hr}$ of storage at $165^{\circ} \mathrm{C}$, but $1 \%$ blends are stable for at least 4 days. A general evaluation of the results indicates that the performance of this bitumen as a binder for road pavement is particularly improved when $1 \%$ of recycled EVA or virgin EVA is added ${ }^{3}$.

The influence of long-chain branching on the foaming behavior of polypropylene (PP) is investigated. Different branching contents are achieved by blending a linear PP (L-PP) and a longchain branched PP (LCB-PP), it improve the optimal foaming process of PPs with a chemical blowing agent, and that additions of the linear material up to $50 \mathrm{wt} \%$ to the LCB-PP ${ }^{4}$.

Thermal, mechanical and fire retardant properties of silane cross linked extra low-density polyethylene (XLPE) containing ethylene-vinyl acetate (EVA) copolymer using incorporation of EVA into XLPE gel content increased and curing time decreased. Mechanical properties of XLPE/
EVA blends improve by increasing EVA content up to $15 \mathrm{wt} \%{ }^{5}$. Study the isotactic polypropylene and ethylene vinyl acetate blends prepared with five different talc concentrations, 3, 6, 9, 12 and 15 wt $\%$, with addition to i-PP/EVA (88/12) to produce ternary composites and find the different mechanical properties those are effected by heat treatments ${ }^{6}$. Prepared composite panels using virgin and recycled high-density polyethylene (VHDPE and RHDPE) and synthesize five types of natural fibers by melt compounding and compression molding. Fiber characteristics and the influences of fiber type and loading rate on HDPE crystallization behavior and composite mechanical properties were investigated 7. Evaluated the effect different filled cross linked thermoplastic elastomers of styrene butadiene rubber (SBR)/high density polyethylene blends (HDPE) blends and prepared using silica, HAFcarbon black, china clay and $\mathrm{TiO}_{2}$. The reinforcement ability of the filler was increased in the order of silica $>\mathrm{HAF}$-black>clay $>\mathrm{TiO}_{2}{ }^{8}$. Investigated the effect of prepared rice husks filled SBR/LLDPE (50/50) blends with a compatibilizer, maleic anhydride (MAH) using a Brabender plasticorder. Increasing MAH concentrations in SBR/LLDPE blends resulted in an increase in the tensile strength, elongation at break and hardness ${ }^{9}$.

Table 1: Composite samples and their corresponding chemical compositions

\begin{tabular}{lcccc}
\hline Sample No. & PP (Wt \%) & LLDPE (Wt \%) & Talc (Wt \%) & $\mathbf{M g C O}_{3}(\mathbf{W t} \%)$ \\
\hline A & 70 & 30 & - & - \\
B & 60 & 20 & 20 & - \\
C & 60 & 20 & - & 20 \\
D & 40 & 20 & 20 & 20 \\
E & 60 & 20 & 10 & 10 \\
\hline
\end{tabular}

Table 2: Thermo-Mechanical Properties of PP/LLDPE/Talc/MgCO ${ }_{3}$ composition

\begin{tabular}{lccccc}
\hline Sample & A & B & C & D & E \\
\hline HDT $\left({ }^{\circ} \mathrm{C}\right)$ & 119.6 & 108.6 & 113.1 & 112.2 & 121.6 \\
Impact resistance $\left(\mathrm{KJ} / \mathrm{m}^{2}\right)$ & 1.181 & 2.804 & 2.120 & 1.648 & 2.623 \\
Charpy Impact resistance $\left(\mathrm{KJ} / \mathrm{m}^{2}\right)$ & 1.190 & 2.872 & 1.817 & 1.590 & 1.842 \\
Tensile strength $\left(\mathrm{Kg}_{\mathrm{f}} / \mathrm{cm}^{2}\right)$ & 68.07 & 79.98 & 68.37 & 32.75 & 57.75 \\
Hardness & 57.6 & 70.7 & 61.4 & 50.7 & 69.3 \\
\hline
\end{tabular}


Synthesize the equal amount of PP/LLDPE and maleic anhydride grafted polypropylene blend systems. The SEM and DSC results of the PP/LLDPE/ WP blend composites showed that WP located itself more in the LLDPE phase. The TGA results show that the MAPP/LLDPE blend and composites are more thermally stable than the PP/LLDPE blend and composites ${ }^{10}$. Focused on the investigation of the changes on thermal, mechanical and morphological properties of PP-LDPE/DAP (90/10/0.06 wt. \%) blend and PP-LDPE/DAP (90/10/0.0 wt. \%) blend when different ratios. With increase in temperature up to $150^{\circ} \mathrm{C}$ the observation of TG/DTG/DTA curves revealed that the thermal stabilities of composites increased usually by increasing amounts of $\mathrm{CaCO}_{3}$ and the blends are incompatible ${ }^{11}$.Evaluated the melt blending of thermoplastic polyurethane (TPU) with polyolefin's (PO's) which reduced the cost and improve mechanical and chemical properties. In addition to that it gives excellent performance in all aspects ${ }^{12}$. In this research work, impact strength of untreated, alkali treated, potassium permanganate treated, benzoyl chloride treated and acrylic acid treated increased with increase in fiber loading up to $60 \%$ and then showed a decline for all untreated and chemically treated areca fiber reinforced epoxy composites ${ }^{13}$.

Talc addition with PP improves the mechanical properties (stiffness, flexural strength, modulus etc) and heat deflection temperature. In this study, the improvements of mechanical properties have shown with increasing suitable percentage (by weight) of talc for new applications ${ }^{14}$. and cellulose acetate $/ \mathrm{Fe}_{2} \mathrm{TiO}_{5}$ nanocomposites have been synthesized successfully. Nanocomposites indicate a ferromagnetic paramagnetic behavior, as evidenced by using vibrating sample magnetometer (VSM) at room temperature ${ }^{15}$. A mononuclear complex of [has been prepared by the reaction of 1-thenoyl-4, 4, 4-trifluoroacetone in a 2:1 molar ratio. ThermoGravimetric (TG) studies of $3-6$ show a great thermal stability up to $400^{\circ} \mathrm{C}$ for polymers, wherein the nickel oxide is formed at higher temperature ${ }^{16}$. Experimental studied ${ }^{17}$ for formulations of $\mathrm{PP}$ and LLDPE viz. 90/10, 80/20, 70/30, 60/40 and 50/50 wt $\%$ were prepared for injection moulding machine. From the work they concluded that It optimum composition of PP/LLDPE blends provided the best mechanical, thermal properties and a moderate rheological property is $70 / 30$. Investigated the effect of incorporation of talc and calcium carbonate PP/ LDPE blend that led to increase the hardness, MFI and melt density while decreased the impact resistance of blend. The results help to fix the optimum composition of (PP/LLDPE/Talc/ $\mathrm{MgCO}_{3}$ ) wt $\%$ at which blend will show excellent thermomechanical properties ${ }^{18}$.

\section{EXPERIMENTAL METHODOLOGY}

The preparation and characterization of Thermo-mechanical properties of polymer composite consist of number of sequential steps, which are as follow:

- $\quad$ Polymer pallets (PP-LLDPE) will be crushed in the powdered form using pulverizer.

- Talcum powder and Magnesium carbonate (powder form) along with PP-LLDPE (powder form) will be mixed uniformly in desired proportion using an agitator.

- $\quad$ This raw material will be fed in Compression Molding Machine (minimum $3 \mathrm{Kg}$ ) at $250^{\circ} \mathrm{C}$ temperature and 50 bar pressure.

- The final product will be in the form of sheets which will be cooled at room temperature and then will be used further for various thermal and mechanical tests.

In this experimental study, five different talc and magnesium carbonate concentrations were added to PP/LLDPE (70/30) to produce composites make up a total of $3 \mathrm{~kg}$. The raw material was first crushed into fine powder form using pulverizer. Talc and $\mathrm{MgCO} 3$ were provided already in fine powder form by LOBA CHEMIE Pvt. Ltd. LLDPE and PP were in granules forms. PP and LLDPE were crushed separately in the pulverizer. Then the powder form $\mathrm{PP} / \mathrm{LLDPE} / \mathrm{Talc} / \mathrm{MgCO} 3$ were mixed uniformly using an agitator. This prepared sample $(3 \mathrm{Kg})$ was then fed into compression molding. The machine was pre heated to $250^{\circ} \mathrm{C}$. Then the upper plate was made to apply pressure of 50 bars on mould, and finally sheets were taken out. It took 03hrs to prepare a single sheet. The processed samples were allowed to cool at room temperature for 48 hours and $50 \pm 5$ $\%$ humidity. Then different mechanical and thermal tests were carried out. PP/LLDPE filled with talc and 
magnesium carbonate to produce PP/LLDPE/Talc/ $\mathrm{MgCO} 3$ composite is shown in table 1 and prepared sample are enlisted in figure 1-5

\section{Analytical Standardization (ASTM)}

The thermal properties of the blends were evaluating through heat deflection temperature (HDT) test. The test was carried out on a Ceast tester machine according to the ASTM D648. The tests specimens were molded in a size of $12.7 \mathrm{~mm}$

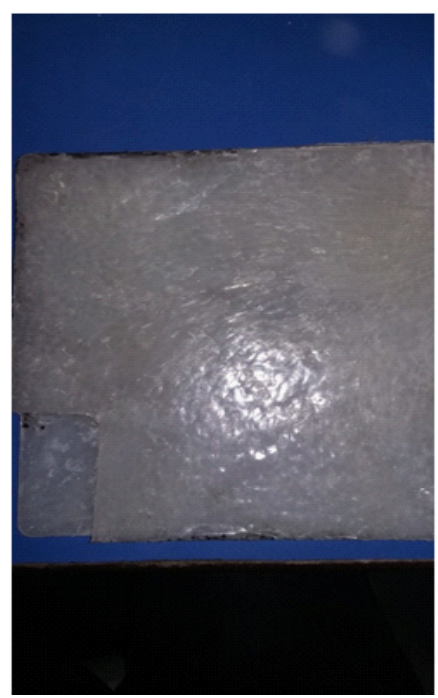

Fig. 1: Composite Sheet of PP/LLDPE 70/30 wt\%

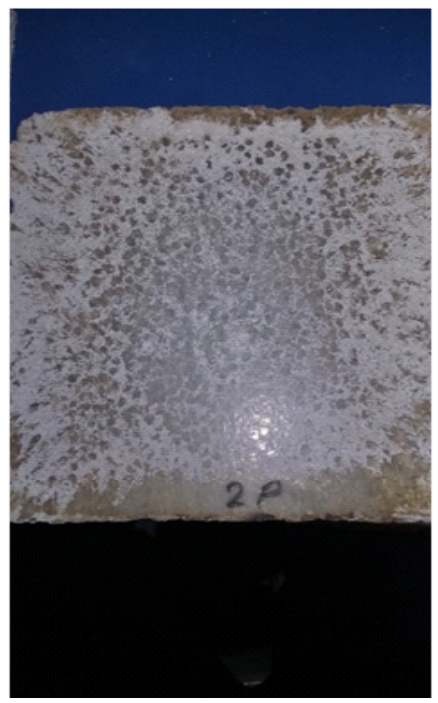

Fig. 2: Composite Sheet of PP/LLDPE/Talc/ $\mathrm{MgCO}_{3} 60 / 20 / 10 / 10$ wt \% (width), $3.2 \mathrm{~mm}$ (thickness). Prior to the test all specimens were kept at room temperature at least $48 \mathrm{~h}$ and $50 \pm 5 \%$ humidity. Izod impact strength values of the blends were evaluated with a Resil impact test instrument according to the ASTM D256 test procedure at room temperature. Izod impact tests specimens were molded in a size of $12.7 \mathrm{~mm}$ (width), $3.2 \mathrm{~mm}$ (thickness) and notched width $10.20 \mathrm{~mm}$. Prior to the test all specimens were kept at room temperature at least $48 \mathrm{~h}$ and $50 \pm 5 \%$ humidity. Izod impact strength values of the blends were evaluated with a Resil impact test instrument according to the ASTM D256 test procedure at room temperature. Izod impact tests specimens were molded in a size of $12.7 \mathrm{~mm}$ (width), $3.2 \mathrm{~mm}$ (thickness) and notched width $10.20 \mathrm{~mm}$. Prior to the test all specimens were kept at room temperature at least $48 \mathrm{~h}$ and $50 \pm 5 \%$ humidity. The hardness test of the composition was carried out on shore $\mathrm{D}$ testing machine according to the ASTM D 2240 and ISO 868. The tensile strength test of the blends was carried out on a universal testing machine according to the ASTM D638. A computer was connected to the load cell and data acquisition program recorded the force measured by the load cell. Test specimens were molded in a size of $12.7 \mathrm{~mm}$ (width) and $3.2 \mathrm{~mm}$ (thickness). Prior to the test all specimens were kept at room temperature at least $48 \mathrm{~h}$ and $50 \pm 5 \%$ humidity.

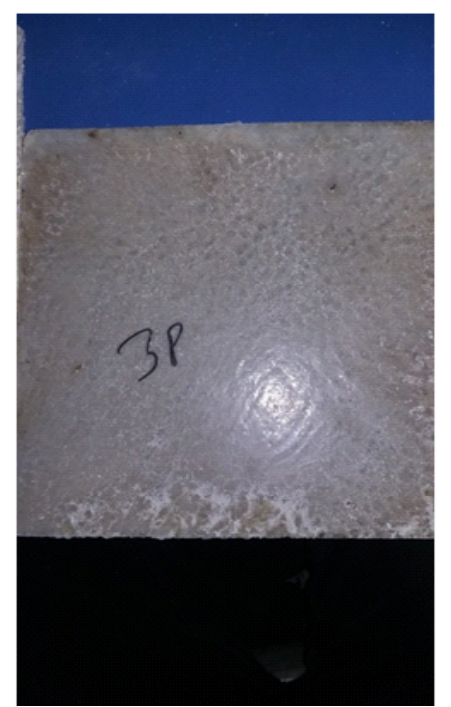

Fig. 3: Composite Sheet of PP/LLDPE/Talc/ $\mathrm{MgCO}_{3} 60 / 20 / 20 / 0$ wt \% 


\section{RESULTS AND DISCUSSIONS}

\section{Heat Deflection Temperature (HDT)}

The heat deflection temperature (HDT) test is used to investigate the thermal properties of PP/LLDPE/Talc/MgCO3 composition. It is the temperature at which a polymer or plastic sample deforms under a specified load. The HDT of PP/ LLDPE/Talc/ $\mathrm{MgCO}_{3}$ compositions are shown in Table 2.

The heat deflection temperature of PP/ LLDPE blend without any filler was $119.6^{\circ} \mathrm{C}$. Addition of $20 \mathrm{wt} \%$ of talc to PP/LLDPE blend decreased the heat deflection temperature to $108.6^{\circ} \mathrm{C}$. Addition of only $20 \mathrm{wt} \%$ of $\mathrm{MgCO}_{3}$ to PP/LLDPE blend increased the HDT to $113.1^{\circ} \mathrm{C}$. Addition of $20 \mathrm{wt} \%$ of talc and $20 \mathrm{wt} \%$ of $\mathrm{MgCO}_{3}$ to PP/LLDPE blend has decreased the heat deflection temperature to $112.2^{\circ} \mathrm{C}$. It is clearly seen that the addition of $10 \mathrm{wt} \%$ of talc and $10 \mathrm{wt} \%$ of $\mathrm{MgCO}_{3}$ to PP/LLDPE has increased the heat deflection temperature to $121.6^{\circ} \mathrm{C}$. The increase in heat deflection temperature of composite may relate to the interaction between PP/LLDPE and Talc/ $\mathrm{MgCO}_{3}$ and this restrict the mobility and deformability of PP/LLDPE, especially for lower contents. Table 2 indicates that the optimum composition percentage

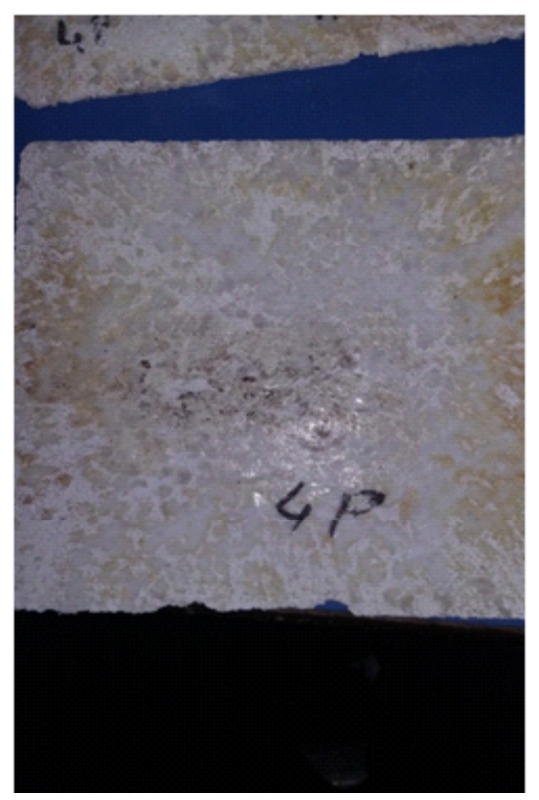

Fig. 4: Composite Sheet of PP/LLDPE/Talc/ $\mathrm{MgCO} 360 / 20 / 0 / 20$ wt $\%$ of PP/LLDPE/Talc/MgCO ${ }_{3}$ provides the best impact strength temperature is $(60 / 20 / 10 / 10)$ wt $\%$.

\section{Izod \& Charpy Impact Strength}

The Izod impact test is used to investigate the mechanical properties of PP/LLDPE/Talc/ $/ \mathrm{MgCO}_{3}$ composition. The impact properties of PP/LLDPE/ Talc/ $\mathrm{MgCO}_{3}$ composition are summarized in Table 2. The impact strength of PP/LLDPE blend without any filler was $1.181 \mathrm{KJ} / \mathrm{m}^{2}$. It is clearly seen that the addition of only $20 \mathrm{wt} \%$ of talc to PP/LLDPE blend increased the impact resistance to highest value of $2.804 \mathrm{KJ} / \mathrm{m}^{2}$. Addition of only $20 \mathrm{wt} \%$ of $\mathrm{MgCO}_{3}$ to blend decreased the impact resistance to $2.120 \mathrm{KJ} / \mathrm{m}^{2}$. The addition $20 \mathrm{wt} \%$ of talc and 20 wt $\%$ of $\mathrm{MgCO}_{3}$ to PP/LLDPE blend has decreased the impact resistance to $1.648 \mathrm{KJ} / \mathrm{m}^{2}$. It is clearly seen that the addition of $10 \mathrm{wt} \%$ of talc and 10 $w t \%$ of $\mathrm{MgCO}_{3}$ to PP/LLDPE blend has increased the impact resistance to $2.623 \mathrm{KJ} / \mathrm{m}^{2}$. The increase in impact resistance of composite may relate to the interaction between PP/LLDPE and Talc/ $\mathrm{MgCO}_{3}$ and this restricts the mobility and deformability of the PP/ LLDPE, especially for lower contents.

The Charpy impact test is used to investigate the mechanical properties of PP/LLDPE/Talc/

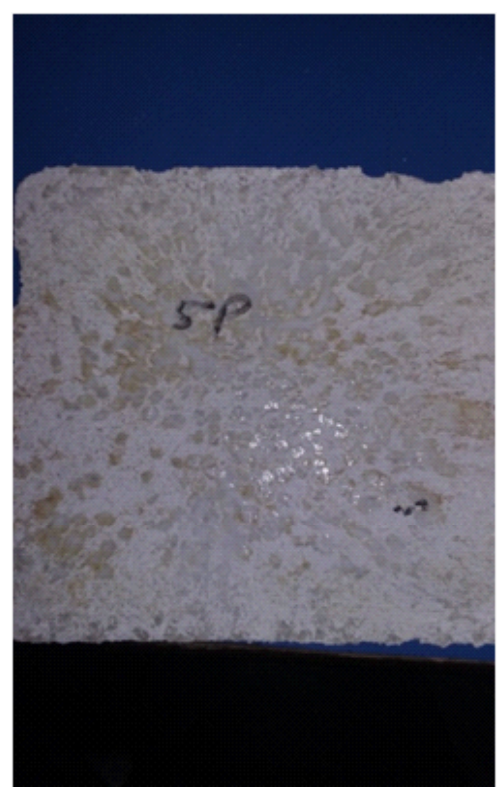

Fig. 5: Composite Sheet of PP/LLDPE/Talc/ MgCO3 40/20/20/20wt\% 
$\mathrm{MgCO}_{3}$ composition. The impact properties of $\mathrm{PP} /$ LLDPE/Talc/ $\mathrm{MgCO}_{3}$ composition are summarized in Table 2. The impact resistance of PP/LLDPE blend without any filler was $1.190 \mathrm{KJ} / \mathrm{m}^{2}$. It is clearly seen that the addition of only $20 \mathrm{wt} \%$ of talc to PP/LLDPE blend increased the impact resistance to highest value of $2.872 \mathrm{KJ} / \mathrm{m}^{2}$. Addition of only $20 \mathrm{wt} \%$ of $\mathrm{MgCO}_{3}$ to blend decreased the impact resistance to $1.817 \mathrm{KJ} / \mathrm{m}^{2}$. The addition of $20 \mathrm{wt} \%$ of talc and 20 wt $\%$ of $\mathrm{MgCO}_{3}$ to PP/LLDPE blend further decreased the impact resistance to $1.590 \mathrm{KJ} / \mathrm{m}^{2}$. It is clearly seen that the addition of $10 \mathrm{wt} \%$ of talc and $10 \mathrm{wt} \%$ of $\mathrm{MgCO}_{3}$ to PP/LLDPE blend increased the impact resistance to $1.842 \mathrm{KJ} / \mathrm{m}^{2}$.

\section{Hardness and Tensile Strength}

The hardness of PP/LLDPE blend without any filler was 57.6. Addition of only $20 \mathrm{wt} \%$ talc has increased the hardness to 70.7. Addition of only 20 wt $\%$ of $\mathrm{MgCO}_{3}$ to PP/LLDPE blend has decreased the hardness to 61.4 . Addition of $20 \mathrm{wt} \%$ of talc and $20 \mathrm{wt} \%$ of $\mathrm{MgCO}_{3}$ to PP/LLDPE blend has decreased hardness to lowest value of 50.7. But it can also be seen that the addition of $10 \mathrm{wt} \%$ of talc and $10 \mathrm{wt} \%$ of $\mathrm{MgCO}_{3}$ to PP/LLDPE blend has increased the hardness to 69.3. The increase in hardness of composite may relate to the interaction between PP/LLDPE and talc/ $\mathrm{MgCO}_{3}$ and this restricts the mobility and deformability of the PP/ LLDPE, especially for lower contents.

The tensile strength of PP/LLDPE blend without any filler was $68.07 \mathrm{Kgf} / \mathrm{cm}^{2}$. It can also be seen that the addition of only $20 \mathrm{wt} \%$ talc to PP/LLDPE blend has increased the hardness to highest value of $79.98 \mathrm{Kgf} / \mathrm{cm}^{2}$. It can also be seen that the addition of $20 \mathrm{wt} \%$ of $\mathrm{MgCO}_{3}$ to PP/LLDPE blend has decreased the tensile strength to 68.37 $\mathrm{Kgf} / \mathrm{cm}^{2}$. Addition of $20 \mathrm{wt} \%$ of talc and $20 \mathrm{wt} \%$ of $\mathrm{MgCO}_{3}$ to PP/LLDPE blend has decreased tensile strength to lowest value of $32.75 \mathrm{Kgf} / \mathrm{cm}^{2}$. Addition of $10 \mathrm{wt} \%$ of talc and $10 \mathrm{wt} \%$ of $\mathrm{MgCO}_{3}$ to PP/LLDPE has decreased the tensile strength to $57.75 \mathrm{Kgf} /$ $\mathrm{cm}^{2}$. The decrease in tensile strength of composite may relate to the interaction between PP/LLDPE and talc/ $\mathrm{MgCO}_{3}$ and this restricts the mobility and deformability of the PP/LLDPE, especially for lower contents.

\section{CONCLUSIONS}

The compositions of PP/LLDPE (70/30) with different percentage of talc and magnesium carbonate fillers were prepared. The work obtained incorporate talc and magnesium carbonate as fillers on PP/LLDPE blend led to increasing the heat deflection temperature (HDT), impact resistance, and hardness. While decreased the tensile strength of PP/LLDPE blend. It is inferred that the optimum composition provided the good thermal properties is PP/LLDPE/Talc/MgCO3 (60/20/10/10) wt\%. It is also concluded that the optimum composition provided the good mechanical properties is PP/ LLDPE/Talc/MgCO3 (60/20/20/00) wt\%. As filler talc \& magnesium carbonate enhanced the thermomechanical properties of PP/LLDPE blend but only at lower wt. \% of talc \& magnesium carbonate. Magnesium carbonate as a filler proved to be costly, so it is not cost effective as talc. Also due to the presence of carbonate ions it can shows rust problems. On the other hand silica, alumina, titanium dioxide can be used at the place of magnesium carbonate which can increase thermo-mechanical properties of PP/LLDPE in future.

\section{REFERENCES}

1. Varughese, K.T., De, P.P., Nando, G. B., \& De, S. K. Journal of Vinyl Technology, 1987, 9(4), 161-167.

2. Berger, Mark J., and Nicole M. Stark. The fourth international conference on wood-fiberplastic composites, 1997, 19-25.

3. Garcýa-Morales M, Partal P, Navarro FJ, Martýnez-Boza F, Gallegos C, González N, González O, Muñoz ME. Fuel. 2004, 83(1),

\section{1-38.}

4. Stange, J. and Münstedt, H., Journal of cellular plastics, 2006. 42(6), 445-467.

5. Azizi, H., Barzin, J. and Morshedian, J., Express Polymer Letter, 2007. 1, .378-384.

6. Oksuz M., Eroglu M, J. Appl. Polymer. Sci. 2005, 98, 1445-1450.

7. Fei Yao, Qinglin Wu, Yong Lei, Yanjun , Industrial Crops and Products 2008, 28, 
$63-72$

8. Jayasree, T. K., \& Predeep, P. Journal of Elastomers and Plastics, 2008 40(2), 127146.

9. A.I. Khalf and A.A. Ward, Materials and Design, 2010, 31, 2414-2421.

10. D. G. Dikobe and A. S. Luyt, Express Polymer Letters, 2010, 4(11) , 729-741.

11. Pirin, K., Balcan, M., \& Doðan, F. Polypropylene, InTech. http://www. intechopen. com/books/ polypropylene, 2012.

12. Merlin Thomas, Atul D. Kamble and Neetha John, Archives of Applied Science Research, 2012, 4 (2), 1191-1202.

13. Dhanalakshmi S, Basavaraju B, Ramadevi P. Orient Journal of Chemistry, 2015, 31(2), 619-627
14. Shri Kant, Urmila, Jitendra Kumar, Gaurav Pundir , International Journal of Research in Engineering and Technology, 2013, 2(4), 411-415

15. Khanahmadzadeh S, Hosseiny GH. Synthesis, Characterization Orient Journal of Chemistry, 2015, 30(4), 1951-1956

16. Al-Anber M. A., Orient Journal of Chemistry, 2015, 29(3), 829-836

17. Hassanien, M.S.S. and Seedahmed, D.A.I., International Journal of Engineering Science and Innovative Technology (IJESIT). 2014. 3(3), 135-141

18. Hassanien M S and Seedahmed A I., International Journal of Engineering Science \& Research Technology. 2015, 4(1), 383387 